\title{
Infliximab attenuates paediatric inflammatory multisystem syndrome in SARS-CoV-2 (PIMS-TS).
}

Joseph Meredith, MBBS ${ }^{\text {a,b }}$; Cher-Antonia Khedim BN, MSc ${ }^{\text {a }}$; Paul Henderson, MBChB, $\mathrm{PhD}^{\mathrm{a}, \mathrm{b}}$; Prof David C. Wilson, Mb BCh, MD ${ }^{\mathrm{a}, \mathrm{b}}$; Prof Richard K. Russell, MBChB, PhD. ${ }^{\mathrm{a}, \mathrm{b}}$

Affiliations: Department of Paediatric Gastroenterology and Nutrition, Royal Hospital for

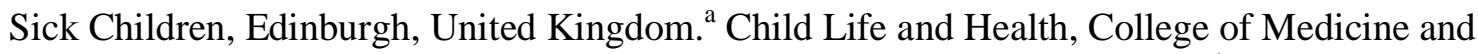
Veterinary Medicine, University of Edinburgh, Edinburgh, United Kingdom. ${ }^{\text {b }}$

Address correspondence to: Joseph Meredith, Department of Paediatric Gastroenterology and Nutrition, Royal Hospital for Sick Children, Sciennes Road, Edinburgh, United Kingdom, EH9 1LF. Email:josephjmeredith@gmail.com

Short title: PIMS-TS attenuated by Infliximab

Table of contents summary: PIMS-TS presentation and course may be attenuated by established infliximab therapy and such medications are potentially key in treating this novel condition.

Funding source: Dr Meredith was supported by an Edinburgh Children's Hospital CharityCatherine McEwan Foundation Research Fellowship, Ferring and Predictimmune.

Conflict of Interest Disclosures: David C Wilson has received speaker's fees, travel support, and participated in medical board meetings with AbbVie, Roche, Nestle Heath Sciences. Richard K. Russell has received speaker's fees, travel support, and participated in medical board meetings with AbbVie, Janssen, Shire, Celltrion, NAPP, and Nestle. 


\begin{abstract}
Abbreviations:
Paediatric inflammatory multisystem syndrome temporally associated with SARS-CoV-2. (PIMS-TS); Multisystem inflammatory syndrome in children (MIS-C); Coronavirus disease 2019 (COVID-19); anti-Tumor Necrosis Factor-alpha (anti-TNF- $\alpha$ ); C-reactive protein(CRP); erythrocyte sedimentation rate (ESR); lactate dehydrogenase (LDH); pyrexia of unknown origin (PUO); intravenous immunoglobulin (IVIG); Polymerase chain reaction (PCR); severe acute respiratory syndrome coronavirus 2 (SARS-CoV-2); hemophagocytic lymphohistiocytosis/macrophage activation syndrome (HLH/MAS); inflammatory bowel disease (IBD); Ulcerative colitis (UC), Paediatric Ulcerative Colitis Activity (PUCAI); intravenous (IV); Royal College of Paediatrics and Child Health (RCPCH); Center for Disease Control (CDC); World Health Organization (WHO); ribonucleic acid (RNA); extracorporeal membrane oxygenation (ECMO); human anti-mouse antibodies (HAMA); anti-drug antibodies (ADA).
\end{abstract}

\title{
Contributors' Statement Page:
}

Dr Joseph Meredith, Dr Paul Henderson, Prof David C. Wilson, Prof Richard K. Russell conceptualised and designed the case report, drafted the initial manuscript, reviewed and revised the manuscript.

Cher-Antonia Khedim, Bachelor of Nursing (BN), Master of Science (MSc), contributed significantly to the care of the patient.

\section{Patient Anonymity and Informed consent:}

The patient and family are aware of the writing of this manuscript and have provided written consent for its publication. 


\begin{abstract}
Paediatric inflammatory multisystem syndrome temporally associated with SARS-CoV-2 (PIMS-TS) is a newly described condition. It has a spectrum of presentations related to hyperinflammation and cytokine storm. We report the first case of PIMS-TS in a child on established anti-Tumor Necrosis Factor-alpha (anti-TNF- $\alpha$ ) therapy; a 10 year-old girl with ulcerative colitis treated with infliximab. The patient had 6-weeks of daily fever with mucocutaneous, gastrointestinal, renal and hematologic involvement. Biomarkers of hyperinflammation were present including: hyperferritinaemia (up to $691 \mu / \mathrm{L}$; normal $15-80$ $\mu \mathrm{g} / \mathrm{L}$ ), C-reactive protein (CRP) (>100mg/L for $>10$ days, normal $0-5 \mathrm{mg} / \mathrm{L}$ ), erythrocyte sedimentation rate (ESR) consistently $>100 \mathrm{~mm} / \mathrm{hr}$ (normal $0-15 \mathrm{~mm} / \mathrm{hr}$ ), raised white cell count with neutrophilia, elevated D-dimer and lactate dehydrogenase (LDH), anaemia and Mott cells on bone marrow analysis.

Extensive investigations for alternative diagnoses for pyrexia of unknown origin (PUO) were negative. The condition was refractory to treatment with intravenous immunoglobulin (IVIG) but improved within $24 \mathrm{hrs}$ of high dose methylprednisolone. Infliximab treatment followed and the patient has remained well at follow up. Polymerase chain reaction (PCR) and serology for SARS-CoV-2 were negative. Current series report such negative findings in up to half of cases. The patient experienced a milder clinical phenotype without cardiac involvement, shock or organ failure. It is postulated that prior anti-TNF- $\alpha$ therapy attenuated the disease course. Infliximab therapy may interfere with serology testing and produce false negative results. This case supports the need for investigation into infliximab as primary therapy for PIMS-TS.
\end{abstract}




\section{What is known on the topic?}

1) Paediatric inflammatory multisystem syndrome temporally associated with SARSCoV-2 (PIMS-TS), also referred to as multisystem inflammatory syndrome in children (MIS-C) temporally related to Coronavirus disease 2019 (COVID-19), is a newly described clinically entity occurring approximately 2-4 weeks post infection.

2) PIMS-TS clinical presentations fall within a spectrum from severe cardiac dysfunction, toxic shock-like syndrome to features indicative of Kawasaki's disease or multisystem hyperinflammation with hemophagocytic lymphohistiocytosis/macrophage activation syndrome (HLH/MAS) features in some.

3) Most cases are severe acute respiratory syndrome coronavirus 2 (SARS-CoV-2) polymerase chain reaction (PCR) negative but serological evidence of previous infection is present in at least half of cases. This, along with temporality and laboratory data, supports the hypothesised post-infectious, immune-mediated nature of the condition.

4) There is no current consensus on optimal therapy. High dose intravenous corticosteroids and IVIG, either alone or in combination, have been used in most cases. Many have required cardiac and circulatory support. Occasional use of biological therapies, including anti-Tumor Necrosis Factor-alpha (anti-TNF- $\alpha$ ) drugs, has also been reported.

\section{What new information does this case contribute?}

1) The PIMS-TS disease presentation and course of illness may be significantly attenuated in the context of established treatment with anti-TNF- $\alpha$ drugs, such as infliximab.

2) Paediatric patients being treated with anti-TNF- $\alpha$ therapies who present with persistent, non-specific features of hyperinflammation - such as pyrexia of unknown origin (PUO) - should have PIMS-TS considered as part of the differential diagnosis and investigated accordingly.

3) Diagnosis of the condition via serology may be complicated by monoclonal antibody therapy such as infliximab.

4) Anti-TNF- $\alpha$ drugs such as infliximab have potential as primary therapy in the management of PIMS-TS. 


\section{$\underline{\text { Introduction }}$}

Paediatric inflammatory multisystem syndrome temporally associated with SARS-CoV-2 (PIMS-TS), also referred to as multisystem inflammatory syndrome in children (MIS-C) temporally related to Coronavirus Disease 2019 (COVID-19), is a newly reported clinical entity. ${ }^{1}$ It is currently understood as a post-infectious, hyperinflammatory, immune-mediated syndrome typically following 2-4 weeks after infection with SARS-CoV-2. It represents a spectrum of disease with overlapping features of toxic shock syndrome, atypical Kawasaki's disease and multisystemic inflammation. While the antecedent infection is frequently mild, patients subsequently present with recurrent fever and symptoms associated with inflammation in one or more organs. Biochemical features of hyperinflammation are present and may resemble an hemophagocytic lymphohistiocytosis/macrophage activation syndrome (HLH/MAS) picture. Cardiac and/or multiorgan dysfunction predominate in many. ${ }^{2-8}$

We report the first case of PIMS-TS in a child on maintenance anti-TNF- $\alpha$ therapy and postulate that this therapy attenuated the clinical phenotype.

\section{Case Report}

A 10yr old female experienced 6 weeks of daily fever exceeding $38.5^{\circ} \mathrm{C}$ having been an inpatient at our regional center from week 3 with previous local hospitalisation. Associated symptoms included rigors, chills, diaphoresis, severe lethargy and oromucosal, aphthous, ulcers. There was bloody diarrhoea and abdominal pain in week 2 of the illness. She also reported dysguesia. Weight loss of $6 \mathrm{~kg}$ (10\% premorbid body weight) was documented over the course. She had bilateral cervical and submandibular lymphadenopathy without respiratory symptoms, rash or other symptoms.

She had been diagnosed 2 years previously with ulcerative colitis (UC) and was treated with infliximab $10 \mathrm{mg} / \mathrm{kg}$ 6-weekly and oral mesalazine 2 grams daily. The most recent infliximab 
dose was 6 weeks before illness onset with a therapeutic trough level of $6.7 \mathrm{mg} / \mathrm{L}$ (range 2-8 $\mu \mathrm{g} / \mathrm{mL}$ ). No anti-drug antibodies were detected. Her UC was in clinical and biochemical remission prior to presentation (faecal calprotectin $37 \mu \mathrm{g} / \mathrm{g}$ four months prior; normal $<50$ $\mu \mathrm{g} / \mathrm{g})$

Family history was significant in terms of mixed racial ethnic background (Polynesian/Caucasian) and a parent with IBD. Weight for age was on the $100^{\text {th }}$ centile $(\mathrm{z}-$ score 2.8), BMI $97^{\text {th }}$ centile (z- score 1.84) based on World Health Organization (WHO) parameters. ${ }^{9}$ A sibling had been unwell with a respiratory illness. Respiratory and cardiac examinations were normal, there was no organomegaly or concerning lymphadenopathy, nor other features indicative of Kawasaki's disease. Ophthalmology, joint, perianal and external genitalia examinations were normal. The Paediatric Ulcerative Colitis Activity (PUCAI) score did not exceed 20 throughout the admission. ${ }^{10}$ Faecal calprotectin on presentation was $1020 u g / g$. Key laboratory values are listed in Table 1.

Of note is the elevated white cell count with neutrophil predominance, elevated C-reactive protein $(\mathrm{CRP})(>100 \mathrm{mg} / \mathrm{L}$ for $>10$ days $)$, hyperferritinaemia, elevated ESR and hypoalbuminemia. There was no hypertriglyceridaemia or hypofibrinogenaemia. Lymphocyte count mostly resided in the low normal range. T cell subsets were normal and IgG levels were raised. D-dimer was elevated at 750ng/mL (normal 0-200ng/mL). Repeated troponin I levels were not elevated. There was evidence of stage 1 acute kidney injury in week 6 and proteinuria was present (urine protein/creatinine ratio $30-108 \mathrm{mg} / \mathrm{mmol}$ [normal $<15 \mathrm{mg} / \mathrm{mmol}]$ ). ${ }^{11}$ Vitamin D level was insufficient (Vitamin D3 level 42nmol/L, normal $>50 \mathrm{nmol} / \mathrm{L}$ ) and she was Epstein-Barr virus and cytomegalovirus naïve.

Extensive infectious disease and immunological investigations were negative. Several SARSCoV-2 PCR throat swabs over the admission were negative as was stool SARS-CoV-2 P 
testing on admission. SARS-CoV-2 IgG in week 5 of illness and post discharge (week 10) were negative (Abbott Architect Immunoassay). ${ }^{12}$ Chest Xray, whole body magnetic resonance imaging, pelvic and abdominal ultrasounds showed no clinically significant abnormality. Serial transthoracic echocardiograms and electrocardiograms were normal. Bone marrow analysis revealed an elevated plasma/lymphocyte count ratio with Mott cells, indicative of immune dysregulation or lymhoproliferation, and known to be a by-product of marked antigenic stimulus. ${ }^{13,14}$ There was no evidence for malignancy or haemophagocytosis. Seven days of IV pipercillin/tazobactam, followed by five days of IV meropenem early in the presentation had little impact on clinical or biochemical parameters.

Following rheumatological and immunological consultation she received 2 grams of intravenous immunoglobulin (IVIG). Given no appreciable clinical response and significant headache afterwards, this was followed by a course of high dose intravenous methylprednisolone (1gram daily for 3 consecutive days). High dose aspirin $(10 \mathrm{mg} / \mathrm{kg} /$ oral/four times daily), proton pump inhibition and adjuvant thromboprophylaxis measures were initiated. Fevers ceased within $<24 \mathrm{hrs}$ from the first steroid dose. The CRP level declined ten-fold within $24 \mathrm{hrs}$ (110 to $12 \mathrm{mg} / \mathrm{L}$ ) and ferritin halved over several days. The patient was discharged with a rapid weaning course of oral prednisolone, low dose aspirin and was administered a $10 \mathrm{mg} / \mathrm{kg}$ intravenous infusion of infliximab in the following week. The patient remains well at follow up 4 weeks post discharge.

\section{$\underline{\text { Discussion }}$}

We report the first case of PIMS-TS (SARS-CoV2 PCR and serology negative) in a patient receiving maintenance anti-TNF- $\alpha$ therapy. The attenuated clinical phenotype in this context 
adds weight to the hypothesised immune-mediated, cytokine-driven pathobiology. It dictates further consideration for such agents as key therapeutics.

PIMS-TS has emerged as a novel clinical entity from April 2020 with approximately 300 reported cases to end of May, 2020. ${ }^{5,15,16}$ Negative PCR testing and evidence of serological conversion in many supports the current understanding of a post-infectious, immunemediated condition. Case definition from the Royal College of Paediatrics and Child Health $(\mathrm{RCPCH})$ and the Center for Disease Control (CDC) does not necessitate PCR or serological confirmation. ${ }^{1,5}$ The largest case series to date, from Public Health France, reports evidence of PCR or serological conversion in 86 of 172 cases (50\%). Interestingly, cases without myocarditis, as in our case, were far more likely to lack PCR or serological evidence. ${ }^{17}$ Unpublished data from London reports 19 of 37 (51\%) cases with IgG positive results and 23 of $37(62 \%)$ with PCR and/or IgG confirmation of SARS-CoV-2. ${ }^{5}$ Verdoni's smaller Italian series reports $20 \%$ negative serology rates and $20 \%$ positive on PCR testing. ${ }^{18}$

Despite evidence for faecal shedding of SARS-CoV in the stool for up to 30 days faecal PCR testing was negative in our patient. ${ }^{19}$ Significant gastrointestinal symptoms and inflammation have been reported with COVID-19 and PIMS-TS and this was a probable cause for the raised faecal calprotectin despite only mild PUCAI score on admission. ${ }^{1,20,21}$ Calprotectin has been shown to be a biomarker of gastrointestinal inflammation in COVID-19 without correlating with faecal ribonucleic acid (RNA) levels. ${ }^{22}$ Multiple infection screens were negative and the clinical picture was not in keeping with an ulcerative colitis flare. 
Case series from the UK, USA, Italy and France report high rates of intensive care admissions for circulatory support. ${ }^{2,17}$ Verdoni described a 30-fold rise in the incidence of Kawasaki's disease in April in Bergamo province with a series of 10 children in whom $60 \%$ had significant cardiac involvement and half had features of shock or MAS. ${ }^{18}$ Belhadjen described 35 cases who required intensive support, including a third with extracorporeal membrane oxygenation (ECMO) requirements. ${ }^{6}$ Similar data is emerging from the USA, with over 100 cases documented from New York State alone. ${ }^{5,8,16}$ Most children have responded well to the different treatment regimens applied. At least five fatalities in PIMS-TS have been reported to date. ${ }^{15}$

While our patient clearly met the case definition for PIMS-TS (recurrent fever, hyperinflammatory biomarkers with mucocutaneous, gastrointestinal, renal and haematologic involvement) her clinical phenotype was far less severe. We hypothesise that her maintenance anti-TNF- $\alpha$ therapy modified her disease course with consistently therapeutic infliximab levels. Infliximab has a terminal half-life approximating ten days (on $5 \mathrm{mg} / \mathrm{kg}$ dose) with prolonged bioavailability, accumulation on repeated dosing and slow clearance rates so would still have been present at the time of presentation. ${ }^{23,24}$

In addition to potentially modifying the disease presentation and course, infliximab also potentially interferes with serological testing for the condition. A caveat from manufacturers of serology testing available at our institution is to interpret with caution in patients receiving treatment with preparations involving mouse monoclonal antibodies. ${ }^{12}$ There is potential interference from human anti-mouse antibodies (HAMA) producing false negatives in assay kits using mouse monoclonal antibodies due to blockade of binding of the diagnostic 
antibody plus other possible mechanisms. False positive results may also occur. ${ }^{25}$ Some manufacturers report using HAMA blockers to reduce such interference but further studies are required to identify the impact of HAMA's in serology testing in the current pandemic. ${ }^{26}$ HAMA's may be distinct from anti-drug antibodies (ADA) which had not been detected previously in our patient. ${ }^{27}$ It is important to be aware of this caveat and it may in part explain the negative serology in this case.

There is no currently established consensus on management of PIMS-TS. IVIG, high dose corticosteroids and less frequently biologicals have been used in a variety of combinations with varying success. ${ }^{2,5,6,8,18}$ Of note, infliximab is used successfully to treat the related condition of Kawasaki's disease. ${ }^{28}$ Aspirin and heparin-based products have been administered for anti-inflammatory purposes and in view of concerns around increased thromboembolic risk. $^{1,29}$

Evidence supporting the role of TNF- $\alpha$ in this syndrome comes from a recent case report from Dolinger and colleagues who showed rapid clinical improvement in a patient with PIMS-TS, receiving primary infliximab treatment in the context of co-presentation with newly diagnosed Crohn's disease. ${ }^{30}$ Concerns around adverse outcomes associated with antiTNF- $\alpha$ treatment and COVID-19 are not supported by current evidence. ${ }^{31,32}$ Evidence implicating a key role of TNF- $\alpha$ in the immune mediated sequalae of COVID-19 are accumulating. ${ }^{29,33,34}$ 
In summary, this first reported case of PIMS-TS in a patient on maintenance anti-TNF- $\alpha$ therapy provides several key insights. The presentation of disease may be attenuated so requires a high index of suspicion. Serologic testing may be negative in up to half of PIMSTS cases, especially in those without myocarditis, so clinical diagnosis is key. Serological assays may be affected by treatment with monoclonal antibodies such as infliximab. Finally, anti-TNF- $\alpha$ therapies warrant further investigation in the primary management of this condition.

\section{References}

1. Royal College of Paediatrics and Child Health. Guidance-Paediatric multisystem inflammatory syndrome temporally associated with COVID-19. https://www.rcpch.ac.uk/resources/guidance-paediatric-multisystem-inflammatorysyndrome-temporally-associated-covid-19. Published 2020. Updated 05/05/2020.

2. Riphagen S, Gomez X, Gonzalez-Martinez C, Wilkinson N, Theocharis P. Hyperinflammatory shock in children during COVID-19 pandemic. The Lancet. doi.org/10.1016/S0140-6736(20)31094-1

3. Viner RM, Whittaker E. Kawasaki-like disease: emerging complication during the COVID-19 pandemic. The Lancet. 2020. doi.org/10.1016/S0140-6736(20)31129-6.

4. World Health Organization. Multisystem inflammatory syndrome in children and adolescents with COVID-19: scientific brief, 15 May 2020. World Health Organization; 2020. WHO/2019-nCoV/Sci_Brief/Multisystem_Syndrome_Children/ 2020.1

5. Center for Disease Control, Center for Preparedness and Response. Multisystem Inflammatory Syndrome in Children (MIS-C) Associated with Coronavirus Disease 2019 (COVID-19) Clinician Outreach and Communication Activity (COCA) Webinar.2020. https://emergency.cdc.gov/coca/calls/2020/callinfo_051920.asp

6. Belhadjer Z, Méot M, Bajolle F, et al. Acute heart failure in multisystem inflammatory syndrome in children (MIS-C) in the context of global SARS-CoV-2 pandemic. Circulation. 2020. doi.org/10.1161/CIRCULATIONAHA.120.048360

7. Toubiana J, Poirault C, Corsia A, et al. Outbreak of Kawasaki disease in children during COVID-19 pandemic: a prospective observational study in Paris, France. medRxiv. 2020. doi.org/10.1101/2020.05.10.20097394 
8. Chiotos K, Bassiri H, Behrens EM, et al. Multisystem Inflammatory Syndrome in Children during the COVID-19 pandemic: a case series. Journal of the Pediatric Infectious Diseases Society. 2020. doi.org/10.1093/jpids/piaa069

9. World Health Organization (WHO). Growth Reference 5-19years. https://www.who.int/growthref/tools/en/. Published 2007.

10. Turner D, Otley AR, Mack D, et al. Development, validation, and evaluation of a pediatric ulcerative colitis activity index: a prospective multicenter study. Gastroenterology. 2007;133(2):423-432. doi: 10.1053/j.gastro.2007.05.029. Epub 2007 May 21.

11. Lameire NH, Bagga A, Cruz D, et al. Acute kidney injury: an increasing global concern. The Lancet. 2013;382(9887):170-179. doi: 10.1016/S0140-6736(13)606479. Epub 2013 May 31.

12. Abbott Laboratory. SARS-CoV-2 IgG Product Information Statement. https://www.fda.gov/media/137910/download. Published 2020.

13. Alanen A, Pira U, Lassila O, Roth J, Franklin RM. Mott cells are plasma cells defective in immunoglobulin secretion. European Journal of Immunology. 1985;15(3):235-242. doi: 10.1002/eji.1830150306

14. Bavle RM. Bizzare plasma cell - mott cell. J Oral Maxillofac Pathol. 2013;17(1):2-3. doi: 10.4103/0973-029X.110682.

15. European Center for Disease Control. Paediatric inflammatory multisystem syndrome and SARS-CoV-2 infection in children - 14 May 2020. ECDC: Stockholm; 2020. https://www.ecdc.europa.eu/en/publications-data/paediatric-inflammatorymultisystem-syndrome-and-sars-cov-2-rapid-risk-assessment\#no-link

16. Morand A, Urbina D, Fabre A. COVID-19 and Kawasaki Like Disease: The KnownKnown, the Unknown-Known and the Unknown-Unknown. In: Preprints; 2020. Morand, A.; Urbina, D.; Fabre, A. COVID-19 and Kawasaki Like Disease: The Known-Known, the Unknown-Known and the Unknown-Unknown. Preprints 2020, 2020050160. doi: 10.20944/preprints202005.0160.v1

17. Public Health France. COVID-19 Weekly Epidemiological Point of May 29, 2020. The Scientific Societies of Infectious Disease, Resuscitation, Emergency Medicine and Pediatrics 2020.

https://www.santepubliquefrance.fr/content/download/256362/document_file/COVID 19_PE_20200529.pdf

18. Verdoni L, Mazza A, Gervasoni A, et al. An outbreak of severe Kawasaki-like disease at the Italian epicentre of the SARS-CoV-2 epidemic: an observational cohort study. The Lancet. 2020. doi.org/10.1016/S0140-6736(20)31103-X

19. Wong SH, Lui RN, Sung JJ. Covid-19 and the digestive system. Journal of Gastroenterology and Hepatology. 2020;35(5):744-748. doi: 10.1111/jgh.15047. Epub 2020 Apr 19 
20. Jin X, Lian J-S, Hu J-H, et al. Epidemiological, clinical and virological characteristics of 74 cases of coronavirus-infected disease 2019 (COVID-19) with gastrointestinal symptoms. Gut. 2020;69(6):1002-1009. doi: 10.1136/gutjnl-2020-320926. Epub 2020 Mar 24.

21. Liang W, Feng Z, Rao S, et al. Diarrhoea may be underestimated: a missing link in 2019 novel coronavirus. Gut. 2020;69(6):1141-1143. doi.org/10.1136/gutjnl-2020320832

22. Effenberger M, Grabherr F, Mayr L, et al. Faecal calprotectin indicates intestinal inflammation in COVID-19. Gut. 2020. doi: 10.1136/gutjnl-2020-321388.

23. Remicade (FDA). Prescribing information. 2017.

http://www.janssenlabels.com/package-insert/product-monograph/prescribinginformation/REMICADE-pi.pdf

24. Rubin DT, Abreu MT, Rai V, Siegel CA. Management of patients with Crohn's disease and ulcerative colitis during the COVID-19 pandemic: results of an international meeting. Gastroenterology. 2020. Apr 6; Pii: S0016-5085(20)20465-0. doi. 10.1053/j.gastro.2020.04.002

25. Klee GG. Human Anti-Mouse Antibodies. Archives of Pathology \& Laboratory Medicine. 2000;124(6):921-923. doi 10.1043/0003-9985(2000)124<0921:Hama>2.0.Co;2

26. https://custombiotech.roche.com/home/featured-solutions/immunoassay-interferenceblocker-portfolio.html.

27. Shankar G, Arkin S, Cocea L, et al. Assessment and reporting of the clinical immunogenicity of therapeutic proteins and peptides-harmonized terminology and tactical recommendations. AAPS J. 2014;16(4):658-673. doi 10.1208/s12248-0149599-2

28. Xue L-J, Wu R, Du G-L, et al. Effect and safety of TNF inhibitors in immunoglobulin-resistant Kawasaki disease: a meta-analysis. Clinical reviews in allergy \& immunology. 2017;52(3):389-400. doi 10.1007/s12016-016-8581-4

29. Jose RJ, Manuel A. COVID-19 cytokine storm: the interplay between inflammation and coagulation. The Lancet Respiratory Medicine. 2020. doi.org/10.1016/s22132600(20)30216-2

30. Dolinger MT, Person H, Smith R, et al. Pediatric Crohn's Disease and Multisystem Inflammatory Syndrome in Children (MIS-C) and COVID-19 Treated with Infliximab. Journal of Pediatric Gastroenterology and Nutrition. 2020. doi 10.1097/MPG.0000000000002809

31. Brenner EJ, Ungaro RC, Gearry RB, et al. Corticosteroids, but not TNF Antagonists, are Associated with Adverse COVID-19 Outcomes in Patients With Inflammatory 
Bowel Diseases: Results from an International Registry. Gastroenterology. 2020; doi:10.1053/j.gastro.2020.05.032

32. Bezzio C, Saibeni S, Variola A, et al. Outcomes of COVID-19 in 79 patients with IBD in Italy: an IG-IBD study. Gut. 2020. doi 10.1136/gutjnl-2020-321411

33. Huang C, Wang Y, Li X, et al. Clinical features of patients infected with 2019 novel coronavirus in Wuhan, China. The lancet. 2020;395(10223):497-506. doi 10.1016/S0140-6736(20)30183-5

34. Gong J, Dong H, Xia SQ, et al. Correlation analysis between disease severity and inflammation-related parameters in patients with COVID-19 pneumonia. MedRxiv. 2020. doi.org/10.1101/2020.02.25.20025643 
Table 1 - Laboratory results summary after hospitalisation on day 16 of fever with relevant maximum or minimum values.

\begin{tabular}{|c|c|c|c|c|}
\hline & & Result & Reference & $\begin{array}{l}\text { On } \\
\text { day* }\end{array}$ \\
\hline $\mathrm{Hb}$ & $(\min )$ & 65 & $115-155 \mathrm{~g} / \mathrm{L}$ & 37 \\
\hline Platelet & $(\min )$ & 323 & $150-400 \times 10^{9} / \mathrm{L}$ & 33 \\
\hline White cell & $(\max )$ & 23.7 & $4.5-14.5 \times 10^{9} / \mathrm{L}$ & 42 \\
\hline Neutrophil & $(\max )$ & 18 & $1.5-8 \times 10^{9} / \mathrm{L}$ & 18 \\
\hline Lymphocyte & $(\mathrm{min})$ & 0.5 & $1.5-7 \times 10^{9} / \mathrm{L}$ & 30 \\
\hline CRP & $(\max )$ & 206 & $0-5 \mathrm{mg} / \mathrm{L}$ & 19 \\
\hline ESR & $(\max )$ & $>130$ & $\mathrm{~mm} / \mathrm{hr}$ & $29-36$ \\
\hline Ferritin & $(\max )$ & 691 & $15-80 \mu \mathrm{g} / \mathrm{L}$ & 37 \\
\hline D-dimer & $(\max )$ & 765 & $0-230 \mathrm{ng} / \mathrm{ml}$ & 33 \\
\hline Fibrinogen & $(\min )$ & 2.9 & $1.5-4 \mathrm{~g} / \mathrm{L}$ & 45 \\
\hline Troponin I & $(\max )$ & $<1$ & $1.0-26.0 \mathrm{ng} / \mathrm{L}$ & 35 \\
\hline LDH & $(\max )$ & 410 & $125-220 \mathrm{U} / \mathrm{L}$ & 38 \\
\hline IgG & $(\max )$ & 22 & $5-16 \mathrm{~g} / \mathrm{L}$ & 25 \\
\hline
\end{tabular}

\begin{tabular}{|c|c|c|c|c|}
\hline & & Result & Reference & On day \\
\hline Sodium & $(\min )$ & 136 & $132-144 \mathrm{mmol} / \mathrm{L}$ & 21 \\
\hline Creatinine & (max) & 86 & $26-57 \mu \mathrm{m} / \mathrm{L}$ & 30 \\
\hline Albumin & $(\mathrm{min})$ & 22 & $28-45 \mathrm{~g} / \mathrm{L}$ & 41 \\
\hline Urine prot/creat & $(\max )$ & 108 & $<15 \mathrm{mg} / \mathrm{mmol}$ & 26 \\
\hline ALT & $(\max )$ & 53 & $0-50 \mathrm{U} / \mathrm{L}$ & 44 \\
\hline Amylase & $(\max )$ & 86 & $24-110 \mathrm{U} / \mathrm{L}$ & 36 \\
\hline Vit D3 & & 42 & $>50 \mathrm{nmol} / \mathrm{l}$ & 50 \\
\hline Infliximab level & & 6.7 & $2-8 \mu \mathrm{g} / \mathrm{mL}$ & $\begin{array}{l}6 \mathrm{wks} \\
\text { prior }\end{array}$ \\
\hline $\begin{array}{l}\text { Anti-drug } \\
\text { antibodies }\end{array}$ & & nil & & $\begin{array}{l}6 w k s \\
\text { prior }\end{array}$ \\
\hline Faecal calprotectin & & 1020 & $<200 \mu \mathrm{g} / \mathrm{g}$ & 14 \\
\hline SARS-CoV-2 IgG & & Negative & & 36 \\
\hline $\begin{array}{l}\text { SARS-CoV-2 PCR } \\
\text { (throat) }\end{array}$ & & Negative & & $\begin{array}{l}10,15 \\
18,29\end{array}$ \\
\hline $\begin{array}{l}\text { SARS-CoV-2 PCR } \\
\text { (faeces) }\end{array}$ & & Negative & & 13,14 \\
\hline Bone marrow & & \multicolumn{3}{|c|}{$\begin{array}{l}\text { Elevated plasma/lymphocyte count ratio } \\
\text { with Mott cells }\end{array}$} \\
\hline
\end{tabular}

*Day of fever 